\title{
ПАРАЛИМПИЙСКИЕ ИГРЫ - ВЫСШЕЕ ДОСТИЖЕНИЕ АДАПТИВНОГО СПОРТА
}

\section{PARALYMPIC GAMES - THE ULTIMATE ACHIEVEMENT OF ADAPTIVE SPORTS \\ M. Motzulev \\ E. Egorycheva}

Summary: In modern society, physical culture and sports are becoming factors in the improvement of man and society. The work traces the history of Paralympic games against the background of the development of adaptive sports in the world, examines the influence of the Paralympic movement on the process of social adaptation and social integration into society of people with disabilities. The main directions of development of adaptive sports are highlighted; stages and peculiarities of its development in Russia and abroad; factors that influenced the formation of Paralympic sports and the Paralympic movement in different countries. The issues of legislative protection of the rights and interests of persons with disabilities, the need for a policy of state paternalism towards them are addressed; considered controversial points of view on participation of persons with disabilities in sports of the highest achievements.

Keywords: people with disabilities, accessible environment, social rehabilitation, adaptive sports, paralympic movement.
Мотиулев Максим Георгиевич

Волжский политехнический институт (филиал) Волгоградского государственного технического университета motcylev@mail.ru

Егорычева Елена Владимировна

Старший преподаватель, Волжский политехнический институт (филиал) Волгоградского государственного технического университета eleg71@mail.ru

Аннотация: В современном обществе физическая культура и спорт становятся факторами совершенствования человека и общества. В работе прослеживается история паралимпийских игр на фоне развития адаптивного спорта в мире, рассматривается влияние паралимпийского движения на процесс социальной адаптации и социальной интеграции в общество лиц с ограниченными возможностями. Выделены основные направления развития адаптивного спорта; этапы и особенности его развития в России и за рубежом; факторы, повлиявшие на становление паралимпийского спорта и паралимпийского движения в разных странах. Затронуты проблемы законодательного обеспечения прав и интересов инвалидов, необходимости политики государственного патернализма по отношению к ним; рассмотрены спорные точки зрения на участие лиц с ограниченными возможностями здоровья в спорте высших достижений.

Ключевые слова: люди с инвалидностью, доступная среда, социальная реабилитация, адаптивный спорт, паралимпийское движение.

\section{Введение}

о данным ВОЗ в мире неуклонно растет количество людей с инвалидностью, в т.ч. детей. На 2016 г. ее имели около 650 млн. человек (10 \% населения земного шара). На 2020 г. их стало более 1 млрд. (23\%). В России на 2021 г. проживало 11 млн. инвалидов. Рост объясняется увеличением численности населения, продолжительности жизни, транспортных трафиков, прогрессом в медицине, ухудшением экологии и проч. Только 20 \% инвалидов трудоспособного возраста, согласно данным, МОТ работают ввиду предвзятого отношения работодателей. Это негативно отражается на их материальном положении, ведет к психологическому дискомфорту. Перед человечеством стоит острая проблема не только физической и социальной реабилитации людей с ограниченными возможностями здоровья (ОВ3), но и интеграции их в общество. Гуманное решение этой проблемы определяет уровень культурного и социального развития общества $[6,4,12]$.

\section{Шель исследования}

Изучение истории возникновения и развития паралимпийского движения и его влияния на социально-экономическое положение лиц с ограниченными возможностями здоровья в мире и их интеграцию в общество.

\section{Материал и методы исследования}

Основой материалов исследовательской работы являются научно-популярные литературные источники, а также новостные электронные ресурсы. Методы исследования - теоретические: анализ литературных источников и обобщение полученных результатов.

\section{Результаты исследования и их обсужкение}

Физическая активность у людей с ОВЗ является, пожалуй, самым эффективным средством их реабилитации. Люди поняли это еще в 17 в. Физическое упражнение способствует восстановлению и поддержанию 
нормальной жизнедеятельности организма, борется с гиподинамией и гипокинезией, формирует и улучшает новые двигательные навыки, восстанавливает душевное равновесие, позволяет вернуться к полноценной и успешной жизни. За рубежом физическая активность давно популярна среди инвалидов с целью отдыха, общения, участия в адаптивном спорте (т.е. спорте для инвалидов), в т.ч. в спорте высших достижений. Именно спортивные достижения людей с ОВ3 обратили внимание на их потенциал и стимулировали законодательное признание их гражданских прав [6,13].

Наибольшее распространение в мире получили три направления адаптивного спорта: паралимпийский, сурдлимпийский и специальный олимпийский [4]. Начало развития адаптивного спорта относят к моменту создания в Берлине первого спортивного клуба для людей с потерей слуха (1888 г.). Первые всемирные игры глухих прошли в Париже в 1924 г. Тогда же образован Международный спортивный комитет глухих (МСКГ). Он объединяет более 90 национальных федераций и каждые 4 года проводит Всемирные игры глухих, с 2001 г. именуемые Сурдлимпийскими. Всероссийское общество глухих (созд. в 1926 г.) вступило в МСКГ в 1957 г. Развитие спорта глухих в современной России связано с созданием в 1992 г. Российского спортивного союза глухих (с 2011 г. - Общероссийская спортивная федерация спорта глухих). Это общественная организация, входящая в состав Олимпийского комитета России $[13,7]$. Специальный олимпийский спорт создан для лиц с нарушением интеллекта американским социологом Юнис Кеннеди Шрайвер. С 1957 г. она возглавляла фонд семьи Кеннеди, имевший целью определить причины умственной отсталости и «улучшить способы обращения общества с гражданами с нарушением интеллекта». На средства фонда в 1968 г. в Чикаго прошли первые международные Специальные олимпийские игры с участием 1000 человек. Международная организация Специальной олимпиады (Special Olympics International) (созд. в 1968 г.) является благотворительной, объединяет более 160 стран мира, признана Международным олимпийским комитетом (МОК) в 1988 г. [7,4]. Специальные олимпиады проводятся каждые 4 года исключительно с целью адаптации людей с нарушениями интеллекта и используют нетрадиционную модель соревнований, согласно которой среди участников нет проигравших. Участниками Специальной олимпиады стало уже более 3 млн. человек. В 1986 г. создана Международная спортивная федерация для людей с нарушениями интеллекта (с 2019 г. - Virtus), благодаря которой спортсмены этой категории могут участвовать в паралимпийских играх [4]. На территории советского и постсоветского пространства специальное олимпийское движение развивалось с 1990 г. Специальная Олимпиада России (созд. в 1999 г.) является национальным комитетом Special Olympics International. В этом движении в нашей стране участвуют более 120 тыс. детей и взрослых, работают более 60 местных отделений $[7,4]$. Казань выбрана для проведения очередных Всемирных Специальных Олимпийских зимних игр в январе 2022 г.

Паралимпийский спорт считается основным направлением адаптивного спорта и объединяет спортсменов с ампутациями конечностей, с церебральным параличом, с поражениями спинного мозга (на колясках) и зрения и категорию «прочие» [4]. Возникновение паралимпийского движения также тесно связано с именем нейрохирурга Людвига Гуттмана, как возрождение современных Олимпийских Игр с именем Пьера де Кубертена. Эмигрировав в 1939 г. из нацистской Германии в Великобританию, Л. Гуттман в 1944 г. возглавил Сток-Мандевилльский центр для лечения и реабилитации военнослужащих с нарушениями опорно-двигательного аппарата (ОДА) в г. Эйлсбери (Англия). Вторая мировая война принесла человечеству огромное количество физически искалеченных людей, которых нужно было возвращать к нормальной жизни. Мир к этому оказался не приспособлен. Достаточно сказать, что серийное производство инвалидных колясок началось только в 1933 г. и для пользования ими нужен был сопровождающий. Л. Гуттман разработал методы ухода за парализованными и их лечения (в т.ч. от инфекций из-за пролежней, дававших большую смертность). Для повышения самооценки и возвращения пациентов к полноценной жизни он ввел в реабилитацию спорт, как обязательную часть комплексного лечения, а в 1948 г. во время Олимпиады в Лондоне организовал для ветеранов-инвалидов на колясках спортивные соревнования по стрельбе из лука, ставшие ежегодными. Целью Л. Гуттмана было создание Олимпийских игр для инвалидов. В 1952 г. была образована Международная спортивная федерация людей с нарушениями ОДА. Общество повернулось лицом к инвалидам и постепенно стало воспринимать их не как «экономическую обузу», а как равноправных граждан, достойных полноценной жизни. Реабилитационные центры в Европе, США, Канаде апробировали различные виды спорта, международные конференции обобщали опыт, дав положительную оценку реабилитационному спорту. Уже с 50-х гг. в Европе начали производить специальные автомобили и строить пандусы. На 9 Сток-Мандевилльские игры в Рим (1960 г.) приехали 400 спортсменов на колясках из 23 стран, которые соревновались в 8 видах спорта (стрельба из лука, легкая атлетика, дартс (метание дротиков в мишень), снукер (разновидность бильярдной лузной игры), плавание, настольный теннис, баскетбол на колясках, фехтование сидя. Среди них были не только ветераны. Эти игры признаны МОК первыми «Паралимпийскими», т.е. параллельными Олимпийским (от греч. «рага» - «около». Л. Гуттман определил их значение как «новой модели интеграции парализованных в общество». В 1964 г. была создана Международная спортивная организация инвалидов, объединившая 16 стран. На первой зимней Паралимпиаде 1976 г. в Шве- 
ции спортсмены с ампутацией конечностей и инвалиды по зрению соревновались в лыжных дисциплинах. С каждым сезоном росло число участников и стран, увеличивалось количество видов спорта. По состоянию на 2021 г. летние игры включают 22 вида спорта, а зимние 5. Проблемы с организацией игр возникли в 1968 г. и в 1980 г., когда города Мехико и Москва приняв Олимпиады, отказались от проведения Паралимпийских игр, ссылаясь первый - на технические трудности, второй - на отсутствие в СССР спортсменов-инвалидов. Благодаря настойчивости Л.Гуттмана игры состоялись соответственно в Израиле и Нидерландах. Последние уже без его участия. Л. Гуттман умер 18.03.1980 г. За выдающиеся заслуги в деле спасения людей от телесных и душевных недугов и возвращения им ощущения гражданской полноценности он отмечен множеством британских и международных наград $[9,13,5]$. А соревнования, изначально задуманные великим доктором с целью лечения и реабилитации инвалидов, стали событием мирового масштаба. Их подготовкой руководит Международный параолимпийский комитет (МПК) (созд. в 1989 г.). Он является международной неправительственной организацией со штаб-квартирой в Бонне (Германия), имеет высший орган - Генеральную ассамблею и исполнительный комитет. Членами МПК являются национальные параолимпийские комитеты (сейчас 161), 5 региональных организаций (по частям света), 10 международных спортивных федераций (по видам спорта) и 4 международные организации спорта для инвалидов (Международная спортивная федерация колясочников и ампутантов, Международная ассоциация спорта и досуга для людей с церебральным параличом, Международная федерация спорта слепых, Международная спортивная федерация для лиц с нарушением интеллекта) [9,1]. МПК призван содействовать паралимпийским ценностям, которые включают в себя мужество, целеустремленность, воодушевление и равенство. На Играх 1988 г. паралимпийцы впервые состязались на объектах города-организатора Олимпиады. С 2002 г. Параолимпийские игры проводились в год проведения Олимпийских на одних объектах, с одним оргкомитетом и финансированием из одних источников. Сборная СССР впервые участвовала в Паралимпийских зимних играх в 1984 г., в летних - в 1988 г. В 2003 г. МПК сформулировал видение и миссию Паралимпийского движения, определив его цели, задачи и роль. Видение состоит в том, чтобы создать для паралимпийцев условия, позволяющие достичь спортивного мастерства, вдохновлять и восхищать мир, способствуя улучшению жизни всех людей с инвалидностью, развивать всех спортсменов от начального уровня до уровня спорта высших достижений, для этого устанавливать связи с внешними организациями и продвигать Паралимпийское движение в целом $[9,13,1]$. Настойчивые усилия МПК по выполнению своей миссии дают положительные результаты. После Игр 1964 г. в Токио, например, все японские паралимпийцы были трудоустроены.
Управление национальной статистики Великобритании в 2018 г. сообщило об увеличении почти на 1 млн. человек, работающих людей с ОВ3 после Паралимпиады 2012 г. в Лондоне. Символ паралимпийского движения красный, синий и зеленый полумесяцы, окружающие одну точку на белом поле. Флаг имеет белый фон с символом в центре. Гимном является пьеса «Гимн будущего» композитора Тьерри Дарниса, слова написал австралийский певец кантри Грэм Коннорс. Девиз «Дух в движении» символизирует сильную волю каждого спортсмена. На играх зажигается огонь. Клятвы спортсменов, судей и тренеров идентичны Олимпийским. Талисманами игр служат сказочные персонажи или фигуры животных [9]. Первенство паралимпийского спорта среди других направлений объясняется наибольшей массовостью спортсменов-участников, стран-участников, видов патологий в здоровье соревнующихся, большей известностью видов спорта в прессе и у широких слоев населения. Кроме того, паралимпийский спорт использует традиционную для здоровых людей модель соревнований, хорошо понятную зрителям. Она включает в себя определение победителей и проигравших, ранжирование участников от лучших к худшим, фиксацию рекордов и социальную оценку спортивных результатов спортсменов. Процедура деления паралимпийцев на группы, уравнивающие их возможности, подобна делению здоровых спортсменов на весовые категории в борьбе и других видах спорта. Организаторы адаптивного спорта считают, что именно при использовании этой модели происходит реальное включение человека с ОВ3 в жизнь общества, усвоение опыта этой жизни, образцов поведения, социальных норм, ролей и функций, вхождение в социальные группы и свойственные им отношения, т.е. достигается главная цель адаптивного спорта - социализация и социальная интеграция инвалидов в общество. Принципиальными являются вопросы использования объектов, мест проживания, проведения досуга; участия в торжественных церемониях и т.д., имеющие место у здоровых спортсменов. Более того, ставится вопрос о совместном, а не поочередном проведении Олимпиад и Паралимпиад [4]. Современный этап развития Паралимпийских игр характеризуется стабилизацией программы, внедрением передовых методик подготовки, увеличением тренировочных и соревновательных нагрузок, использованием внетренировочных факторов, и, как результат, повышением конкуренции и сменой традиционных лидеров. Улучшение качества спортивного инвентаря и оборудования (протезов, облегченных колясок и др.) привело к росту мировых и паралимпийских рекордов [1].

Паралимпийский спорт в настоящее время выступает системообразующим фактором, вокруг которого осуществляются интеграционные процессы, происходящие в адаптивном спорте [4]. Адаптивный спорт в Европе развивался активнее, чем в России. Так, во Франции в 1995 г. из 1 млн. умственно отсталых людей 23 тыс. зани- 
мались спортом и посещали 550 муниципальных спортивных клубов. Но, пожалуй, нигде так масштабно, как в США, не исполняли Закон о лицах с ОВЗ (принят в 1990 г.). Он явился результатом длительной (с 60-х гг.) и активной борьбы инвалидов за свои права. В ходе акции протеста «Ползком на Капитолий» в 1990 г. часть митингующих оставили инвалидные коляски и на руках штурмовали лестницы Капитолия, доказав конгрессменам необходимость принятия этого закона и создания для инвалидов доступной среды. Закон запретил дискриминацию по признаку инвалидности, расширил гражданские права людей с ОВ3 за пределы территорий, финансируемых из федерального бюджета. Инвалидность из личной проблемы превратилась в проблему общества. Инвалидов поддерживали суды. Общественные организации инвалидов формировали группы поддержки в борьбе против дискриминации. Сейчас никого не удивляет человек на коляске с электроприводом, независимо передвигающийся по городу (есть пандусы, дорожки для инвалидов, парковки для их автомобилей, подъемники в автобусах и такси). В общественных зданиях, дворцах спорта, на стадионах, в магазинах создана доступная среда (лифты, зрительские места с инвалидными креслами, спецтуалеты, спецраздевалки и проч.). Многие понимают педагогический смысл совместного обучения здоровых детей и детей-инвалидов: у здоровых развивается социальная совесть, а дети-инвалиды учатся жить в мире здоровых людей. Жилые дома проектируют с учетом требований инвалидов. С 90-х гг. общественные организации инвалидов пропагандируют философию независимой жизни. Они не согласны с изолированием инвалидов в спецзаведения, считая, что в них создаются тепличные условия, что приводит к иждивенчеству и беспомощности людей с ОВ3 и требуют новых подходов в государственной системе социальной помощи. В настоящее время физкультурно-оздоровительная и спортивная работа среди инвалидов в США опирается на законодательные акты, уравнивающие права инвалидов с другими категориями населения (спортсооружения и транспорт доступны), начинается с детского возраста, опирается на прочную теоретическую базу (программы разрабатываются в учебных и научных центрах). Американский пример вдохновил людей с ОВ3 во всем мире на борьбу с многовековой изоляцией, стереотипами и страхами. Основатель движения за гражданские права инвалидов в Америке Джуди Хьюман признана во всем мире как лидер сообщества людей с ОВ3 $[6,8]$.

В мировом масштабе 13.12.2006 г. ООН приняла Конвенцию «О правах инвалидов» (вступила в действие 03.05.2008 г.), которая является международным договором и имеет обязательную силу для стран-членов $\mathrm{OOH}$, подписавших и ратифицировавших ее. По состоянию на ноябрь 2019 года в конвенции участвуют 181 государство и Евросоюз. Этим документом мировое сообщество признало, что люди с инвалидностью имеют такие же права, как и все остальные граждане, и должны иметь равные возможности в реализации своих прав. Вместо доминировавшего ранее «медицинского» подхода к инвалидности был закреплен «социальный». Конвенция подписана Россией в 2008г., ратифицирована в 2012 г. [2]. Концепция равного гражданства расценивает людей с ОВ3 не как лиц с «остаточной трудоспособностью», а как достойных граждан, потребителей специфических товаров и услуг. Политика их социальной поддержки включает в себя следующее: государство отвечает за устранение условий, ведущих к инвалидности, и решение вопросов, связанных с последствиями инвалидности; обеспечивает инвалидам возможность достигнуть одинакового со своими согражданами уровня жизни, в т.ч. в сфере доходов, образования, занятости, здравоохранения, участия в общественной жизни; инвалиды имеют право жить в социуме, общество порицает их изоляцию и стремится создать условия независимой жизни (самообеспечение, самодостаточность, безбарьерная среда); за инвалидами признаются права и обязанности граждан данного общества; в компетенции государства находятся способы признания, обеспечения и реализации прав и обязанностей инвалидов, как членов общества [3].

В соответствии с новыми установками в мире формируется дисциплина и профессия, получившая международное название «Адаптивная физическая активность» (АФА). Международная федерация АФА издает тематический журнал и публикует обзоры научных исследований в издательстве Human Kinetics с передовой информацией в данной области. В России новая специальность «физическая культура для лиц с отклонениями в состоянии здоровья (АФА)» открыта с 1996 года.

Организационные структуры адаптивного спорта, оздоровительные программы и их правовое обеспечение в разных странах различны, что объясняется разным уровнем их социально-экономического положения. Развитие адаптивной физической культуры и спорта (АФКиС) за рубежом и подготовка элитных спортсменов-инвалидов осуществляется в основном с помощью общественных организаций при поддержке органов государства. Особенностями отдельных стран являются: создание социальных центров благосостояния для лиц с ОВ3 (Япония); использование деятельности религиозных христианских общин (США); проведение Национальной Лотереи, средства от которой направляются на обеспечение систематических занятий адаптивным спортом (Великобритания); открытие спортивных академий для получения физкультурного образования лицами с ОВ3 (Франция). В вузах некоторых стран создана образовательная программа по спортивному управлению бизнесом. В России решение проблем реабилитации инвалидов осуществляется преимущественно на государственном уровне. Несмотря на довольно боль- 
шое количество нормативно-правовых актов по вопросам адаптивного спорта, требуется дальнейшее совершенствование законодательства с учетом специфики этого спорта и Паралимпийского движения [1]. Авторы, изучающие АФКиС в России, выделяют несколько периодов их развития в нашей стране, начиная с появления первых форм занятий с инвалидами по слуху и зрению в конце 19 в. и становления адаптивного спорта в СССР с момента создания Федерации спорта инвалидов при Горспорткомитете Ленинграда (1980 г.) до современного этапа развития в новой России, характеризующегося возрастанием роли государства. Периоды спада в развитии АФКиС объясняются экономической и политической обстановкой в стране. Так в 1992-1996 гг. отмечалось снижение массовости адаптивного спорта из-за резкого уменьшения государственного финансирования в связи с распадом СССР и экономической политикой, получившей название «шоковая терапия». С созданием в 1996 г. Паралимпийского комитета России (ПКР) наметился определенный прогресс в подготовке спортсменов-инвалидов к соревнованиям высшего ранга [7]. Однако, по данным Госкомспорта России из 10 млн. инвалидов в стране на тот момент АФКиС занималось всего 29 тыс. человек, т.е. 0,29\%. Причинами назывались отсутствие необходимой законодательной базы и финансирования, специализированных спортсооружений и оборудования, сложность перемещения в общественном транспорте, недостаток кадров, и, как следствие, отсутствие в достаточной степени желания у самих инвалидов. Для решения этих проблем в 1999 г. впервые была разработана Концепция государственной политики РФ в области физической реабилитации и социальной адаптации инвалидов средствами физкультуры и спорта (на 2001-2004 гг.). В 2006 г. была принята Федеральная целевая программа (ФЦП) «Развитие физкультуры и спорта в РФ на 2006-2015 годы», в рамках реализации которой построено более 200 стадионов, ледовых катков, бассейнов и спорткомплексов. ФЦП предусматривала бесплатный и льготный доступ к спортсооружениям для инвалидов, детей и малообеспеченных граждан $[13,7]$. Однако т.н. Закон о монетизации льгот (№122-Ф3 от 22.08.2004г.), принятый в связи с политикой ограничения вмешательства государства в экономическую деятельность субъектов предпринимательства, резко ухудшил положение инвалидов и их организаций, отняв мотивацию к трудоустройству, учебе, интеграции в общество. К моменту подписания вышеназванной Конвенции ООН страна оказалась в начале пути по реализации ее основных положений [2]. С 2009 г., когда пришло понимание того, что государственный патернализм в отношении инвалидов просто необходим ввиду заведомой неконкурентоспособности в условиях рыночной экономики, началось софинансирование и субсидирование из средств федерального бюджета мероприятий в регионах РФ по созданию и сохранению рабочих мест для инвалидов, условий для их профобучения, решению других соци- альных вопросов. С 2011 г. заработала ФЦП «Доступная среда» [2]. С начала ее реализации общий объем финансирования составил 423 млрд. рублей. За это время оборудовано для инвалидов 27 тыс. различных объектов, 7,4 тыс. детсадов, 9,8 тыс. школ, 67 учреждений по АФКиС (сведения на октябрь 2021 г.). Дальнейшее финансирование программы составит в 2021 г. - 58,9 млрд. руб., в 2022 г. - 59 млрд., и в 2023 г. - 59,9 млрд. руб. Действие ФЦП продлено до 2025 г. [10]. Поскольку «организация и проведение межрегиональных, всероссийских и международных официальных спортивных соревнований среди инвалидов, лиц с ОВЗ» (ст. 6 Ф3 «О физической культуре и спорте в РФ») относится к федеральным полномочиям, Паралимпийский спорт высших достижений достаточно хорошо поддерживается сейчас на уровне федерального законодательства. Приняты меры по социальной поддержке спортсменов, тренеров, специалистов. Решен вопрос о приравнивании статуса паралимпийцев к статусу олимпийцев. Спортсменам-победителям и призерам Паралимпиад и их тренерам, выделяются денежные вознаграждения, учреждены президентские стипендии членам сборных команд России по паралимпийским видам спорта, уравнены объемы денежных вознаграждений за призовые места на Олимпийских и Паралимпийских играх. Чемпионы Паралимпийских игр имеют право на ежемесячное дополнительное материальное обеспечение в размере $250 \%$ социальной пенсии, налоговые льготы в отношении полученных на играх наград. Им предоставлено право без экзаменов поступать в вузы. Отдельной строкой в госбюджет включена фиксированная сумма на подготовку спортсменов к Паралимпийским играм. Укреплению межнациональных отношений способствует «Модельный закон о Паралимпийском спорте» для государствучастников СНГ (от 25 ноября 2008 г.) [13]. Немаловажное значение имеет расширение международных контактов спортсменов-инвалидов. Пропаганде паралимпийского движения в стране значимо способствовала Паралимпиада в Сочи (2014 г.). В 2009 г. в Москве впервые по инициативе МОК и оргкогмитета «Сочи-2014» отмечался Международный паралимпийский день, событиями которого стали показательный международный матч по следжхоккею и награждение паралимпийцев-лауреатов ежегодной премией ПКР «Возвращение в жизнь». Оргкомитет «Сочи-2014» разработал комплексную программу по повышению осведомленности населения о паралимпийском движении с целью изменения отношения общества к инвалидам в стране в целом. Инфраструктуры, созданные для игр, стали моделью безбарьерной среды для всей России. В образовательные программы по подготовке кадров для индустрии спорта, гостеприимства и сервиса были включены основы знаний в области Паралимпийского движения, этики общения с людьми с ОВ3, современной терминологии, прививающей равноправное отношение к людям с ОВ3 [9]. В 2012 г. создан социальный телеканал «Инва Медиа ТВ» для лиц с ОВ3, целе- 
вая аудитория которого составляет более 35 млн. человек. К сожалению, не обошли наш паралимпийский спорт проблемы допинга. Из-за допингового скандала наши спортсмены не участвовали в Паралимпиаде-2016, на Паралимпиаде-2018 выступали в качестве нейтральных, на Паралимпиаде-2020 в Токио (2021 г.) им запретили выступать под флагом РФ. Это не сломило дух наших спортсменов. Они привезли из Японии рекордное количество в истории сборной медалей (118). Одним из регионов, где АФКиС развиваются наиболее активно, является Волгоградская область. С 2014 г. в регионе введено более 160 новых спортобъектов. С 2005 г. работает ГАУ ВО «Центр спортивной подготовки по адаптивным видам спорта». С 2017 г. при Волгоградской государственной академии физкультуры функционирует научно-практический центр адаптивной физкультуры для детей с ОВ3 «Без границ». В 2019 г. создан специальный сайт и канал YouTube в рамках реализации социального проекта «База знаний по адаптивному спорту», где размещено более 200 видеороликов по видам адаптивного спорта, доступным для людей с ОВ3 в регионе. С 2021 г. в г. Михайловка создан мобильный центр адаптивной физкультуры «Эдельвейс» при поддержке Фонда президентских грантов. С 1997 г. существует в Волгограде своя футбольная команлда инвалидов-ампутантов СКИ «Академия» [7]. В Паралимпиаде-2020 участвовали трое волгоградских спортсменов: пловцы Андрей Гладков (выиграл золото), Наталия Буткова (серебро и бронза) и байдарочница Мария Никифорова (4 место). Вернувшихся на родину спортсменов встречали как героев. Надо отметить, что волгоградцы знают и любят своих паралимпийцев. Задержка с церемонией их награждения в регионе вызвала резкую критику СМИ в адрес облкомспорта. Победители и их тренеры заслуженно получили награды и денежные вознаграждения от региона.

\section{Зак^ючение}

Адаптивный спорт ориентирован на соревновательную деятельность и достижение максимальных результатов. Некоторые авторы и часть населения считают, что спорт для инвалидов приобретает профессиональный характер. Выступление на соревнованиях требует от спортсмена физического и психологического напряжения, которых порой не выдерживает даже здоровый человек. В связи с этим они высказываются против таких занятий спортом. В 2015 г. студенческое научное общество Амурского медколледжа, где учатся студенты с ОВ3 по слуху, провело анкетирование по спорной теме. 71\% опрошенных из числа здоровых студентов высказались против проведения паралимпийских игр, а 97\% опрошенных из числа студентов с ОВЗ считают их проведение правильным. Паралимпийцы показывают другим людям, что инвалидность - не приговор. Нужно только захотеть. Значит, государство и общество обязаны уважать выбор людей с ОВ3 и помочь им «захотеть» изменить себя и весь мир. При этом надо учитывать особенности этих людей, не оставлять их наедине со своими проблемами и преодолевать социальные барьеры в обществе [11]. Для современной России физкультура и спорт являются важной составляющей государственной политики по пропаганде здорового образа жизни, формирующей лучшие личные качества человека. Радует, что равноправным субъектом этой политики становятся, наконец, люди с ОВ3.

\section{ЛИТЕРАТУРА}

1. Блохин С.А., Гейко Г.Д., Хайруллин А.Г., Хисамутдинов В.Х., Халиуллин Р.Х. Современное состояние и тенденции развития адаптивного спорта в России и за рубежом // Ученые записки университета Лесгафта. - 2019. - № 1 (167). - С 34-39.

2. Волкова Г.Н. Конвенция ООН «0 правах инвалидов» и эволюция российского законодательства // Народонаселение. - 2014. - №1 (63). - С. 19-30.

3. Государственная политика в отношении инвалидов и нетрудоспособных [Электронный ресурс]. URL: https://studbooks.net/626035/sotsiologiya/ gosudarstvennaya_politika_otnoshenii_invalidov_netrudosposobnyh

4. Евсеев С.П. Адаптивный спорт [Электронный ресурc]. URL: http://sportwiki.to/\%D0\%90\%D0\%B4\%D0\%B0\%D0\%BF\%D1\%82\%D0\%B8\%D0\%B2\%D0\%BD\%D 1\%8B\%D0\%B9_\%D1\%81\%D0\%BF\%D0\%BE\%D1\%80\%D1\%82

5. История невролога, который пережил Холокост и изобрёл Паралимпийские игры [Электронный ресурс]. URL: https://tsimmes.ru/istoriya-nevrologakotoryj-izobryol-paralimpijskie-igry/

6. Куликова А.И., Шамшурова М.Ю. Жизнь людей с ограниченными возможностями в России и США // Символ науки. - 2016. - №3-1. - С. 95-99.

7. Махов А.С., Степанова 0.Н. Периоды становления и развития адаптивного спорта в России // Электронная версия журнала «Адаптивная физическая культура». - 2013. - №2 (54). - С. 2-5.

8. От фрик-шоу до независимости. Как в Америке боролись за права людей с инвалидностью [Электронный pecypc]. URL: https://mioby.ru/novosti/ot-frikshou-do-nezavisimosti-kak-v-amerike-borolis-za-prava-ljudej-s-invalidnostju/

9. Паралимпийская терминология. Краткий справочник. М.: Оргкомитет «Сочи 2014», ИД «Коммерсантъ», 2010. - 98 с.

10. Сайт Министерства социального развития [Электронный ресурс]. URL: https://bezbarierov.permkrai.ru/node/24801

11. Сидоренко М.А., Пархоменко 0.С. Параолимпийские игры и здоровье людей с ограниченными возможностями [Электронный ресурс]. URL: https://www.informio.ru/publications/id1283/Paraolimpiiskie-igry-i-zdorove-lyudei-s-ogranichennymi-vozmozhnostjami 
12. Статистика инвалидов в мире [Электронный ресурс]. URL: https://vawilon.ru/statistika-invalidov-v-mire/

13. Хасанова Л.Р., Иванов В.Д. Паралимпийское движение: особенности развития и правового регулирования в Российской Федерации // Физическая культура. Спорт. Туризм. Двигательная рекреация. - 2016. - №3. - С.79-82.

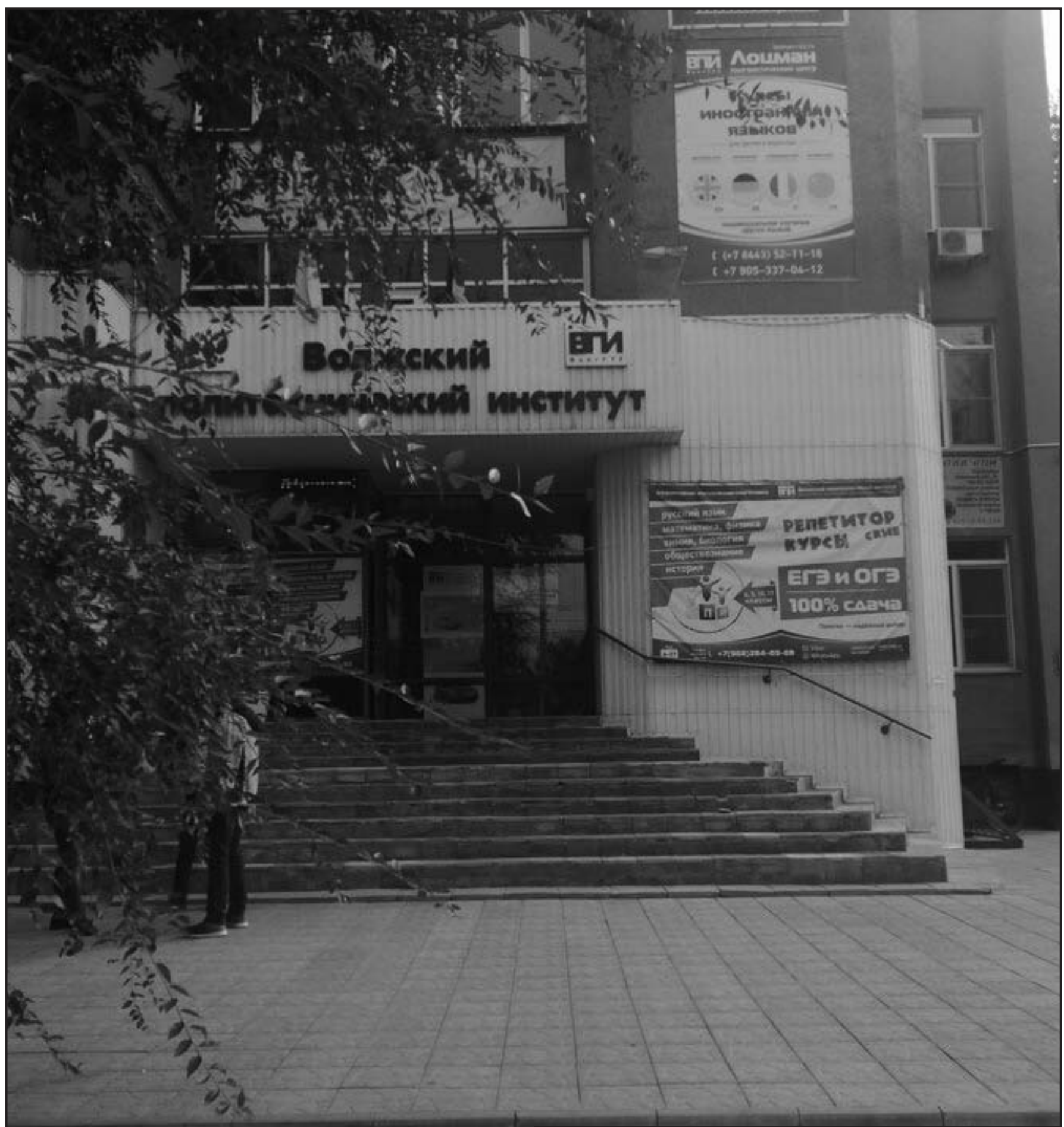

Волжский политехнический институт (филиал) Волгоградского государственного технического университета 